\title{
Speleothem isotope records for climate model evaluation
}

\author{
Nikita Kaushal' and Laia Comas Bru² \\ Second SISAL meeting, Stockholm, Sweden, 20-22 September 2017
}

PAGES' SISAL (Speleothem Isotope Synthesis and Analysis) working group is creating a systematic global synthesis of speleothem isotopic records (Comas Bru et al. 2017a). Beyond the creation of the database, SISAL also aims to understand and showcase how speleothem data can be used in paleoclimate modeling studies. Data synthesis combined with suitable modeling targets can help reduce uncertainty and improve interpretations in both. Such data-model comparisons can also help refine our quantitative understanding of past climate events and enhance credibility of model projections (Schmidt 2010). At the time of this workshop, we had 208 of 577 speleothem-based climate records in the database with more records being added every week (see Fig. 1 in Comas Bru et al. 2017b for a global map with identified records). The first version of the SISAL database will be released in early 2018 .

Seventeen SISAL members (including eight early-career researchers and six researchers from the PMIP modeling community) met to discuss isotope-enabled model evaluations using the database and how the SISAL database should be made available to end-users such as the paleoclimate modeling community. The meeting took place at the Navarino Environmental Observatory in Stockholm, Sweden, and was organized by a group of SISAL members from different universities. On Day 1, participants presented research on prospects for speleothem-model evaluations targeting specific climate questions, periods and regions. Presentations were also given by stakeholders such as IsoNet (Isotopes for Tropical Ecosystem Studies) and the proxy data synthesis working group of PalMod (www.palmod.de). This was followed by a discussion on the best-practice methods to quantify uncertainties on the age and isotope measurements in SISAL and the most convenient way for modelers to understand and incorporate these uncertainties when using the database. There were subsequent discussion sessions on proof-of-concept exercises using SISAL and existing isotope-enabled simulations. These discussions were formalized through breakout sessions, where tasks were delegated to SISAL members. Throughout the day, we identified gaps in data coverage for key time periods in specific regions.

Day 2 kicked-off designing the contents of the SISAL presentation for the PMIP4 meeting the following week to showcase the major features of the interim SISAL

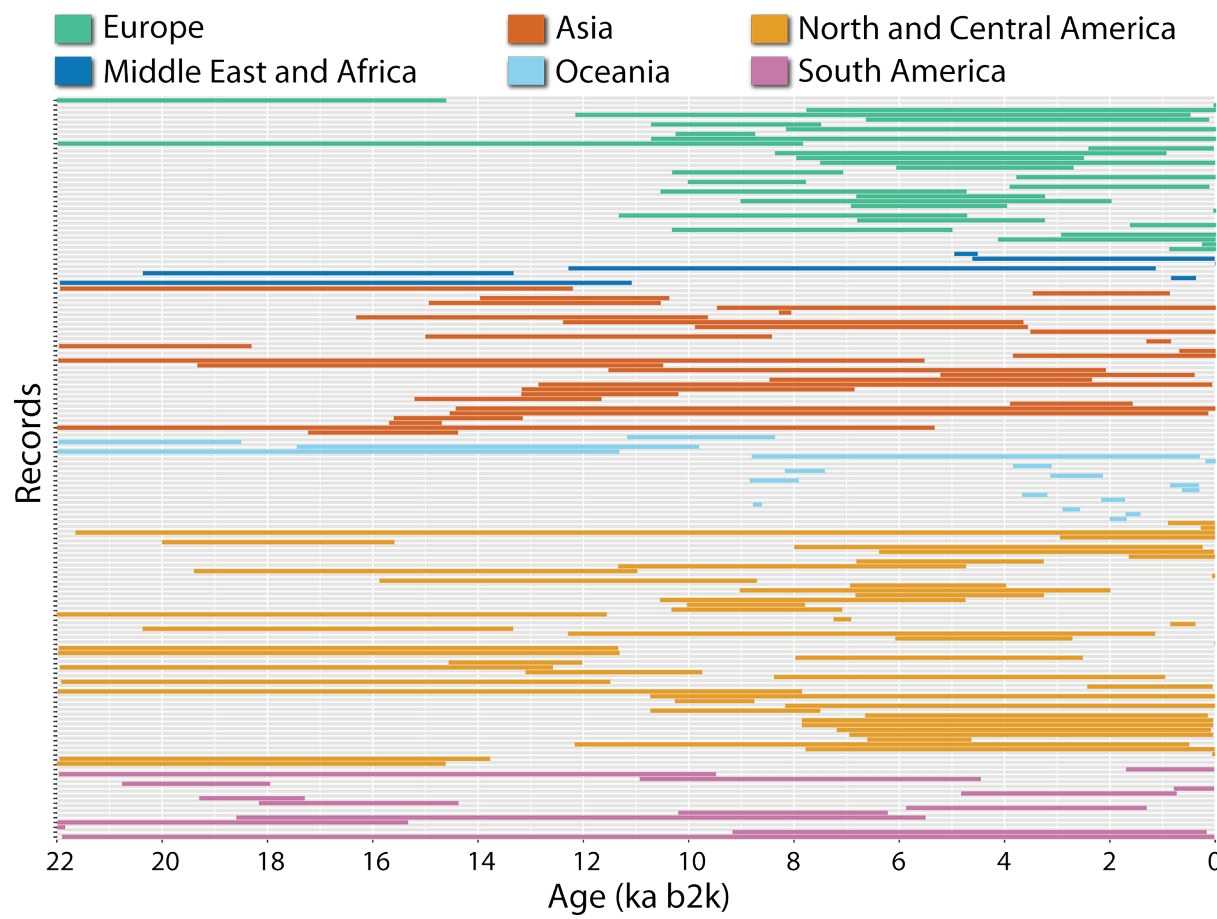

Figure 1: Time coverage of the records $(n=208)$ in SISAL_v0 (September 2017) for different regions: Europe (36$\left.75^{\circ} \mathrm{N}, 30^{\circ} \mathrm{W}-30^{\circ} \mathrm{E}\right)$, Middle East and Africa $\left(45^{\circ} \mathrm{S}-36^{\circ} \mathrm{N}, 30^{\circ} \mathrm{W}-60^{\circ} \mathrm{E}\right)$, Asia $\left(10-60^{\circ} \mathrm{N}, 60-130^{\circ} \mathrm{E}\right)$, Oceania $\left(10-60^{\circ} \mathrm{S}\right.$, $\left.90-180^{\circ} \mathrm{E}\right)$, North and Central America $\left(10-60^{\circ} \mathrm{N}, 50-150^{\circ} \mathrm{W}\right)$ and South America $\left(60^{\circ} \mathrm{S}-10^{\circ} \mathrm{N}, 30-150^{\circ} \mathrm{W}\right)$

database (Fig. 1). This was followed by a discussion on how to address key questions related to the climate interpretation of speleothem isotopic data using paleoclimate model outputs. Lastly, there were handson sessions centered on advancing the first publications emerging from the SISAL database. Sections of the paper describing the database were jointly written by SISAL members in multiple breakout sessions and further papers focusing on specific climate questions were outlined. These outlines will be shared with the wider SISAL community to give it the opportunity to participate in the projects. Day 2 also saw a short presentation on the PAGES working group DAPS (Paleoclimate Reanalyses, Data Assimilation and Proxy System Modelling) to identify possible synergies to emerge from a SISAL-DAPS collaboration. We decided to organize short meetings with both groups at widely attended, large geoscience conferences in 2018 to promote further discussions. Day 3 brought the workshop to a close with a recap discussion on our next steps towards SISAL's third meeting in October 2018 and developing a timeline for the working group's future activities.
SISAL encourages ideas for big data analyses that can be achieved with this new dataset. For more information about SISAL or how to get involved, go to http://pastglobalchanges.org/ini/wg/sisal

\section{ACKNOWLEDGEMENTS}

We thank PAGES, the University of Reading, University College Dublin, Navarino Environmental Observatory in Stockholm University, Savillex and John Cantle for their financial support.

\section{AFFILIATIONS}

'Department of Earth Sciences, University of Oxford, UK ${ }^{2}$ School of Earth Sciences, University College Dublin, Ireland

\section{CONTACT}

Nikita Kaushal: nikitageologist@gmail.com REFERENCES

Comas Bru L et al. (2017a) PAGES Mag 25: 129 Comas Bru L et al. (2017b) PAGES Mag 25: 156

Schmidt GA (2010) J Quat Sci 25: 79-87 